\title{
Prostate volume as an independent predictor of prostate cancer in men with PSA of 10-50 $\mathrm{ng} \mathrm{ml}^{-1}$
}

\begin{abstract}
Ping Tang ${ }^{1}$, Xiao-Long Jin ${ }^{2}$, Matthew Uhlman ${ }^{3}$, Yu-Rong Lin ${ }^{1}$, Xiang-Rong Deng ${ }^{1}$, Bin Wang ${ }^{1}$ and Ke-Ji Xie ${ }^{1}$
Prostate volume (PV) has been shown to be associated with prostate cancer $(\mathrm{PCa})$ detection rates in men with a prostate-specific antigen (PSA) in the 'grey zone' (2.0-10.0 $\mathrm{ng} \mathrm{ml}^{-1}$ ). However, the PSA 'grey zone' in Asian men should be higher because the incidence of PCa in Asian men is relatively low. Therefore, we evaluated the association between PV and PCa detection rates in men with PSAs measuring 10-50 $\mathrm{ng} \mathrm{ml}^{-1}$. Men who underwent a 13-core prostatic biopsy with PV documentation participated in the study. A multivariate stepwise regression was used to evaluate whether the PV at time of prostate biopsy could predict the risk of PCa. The rates of PCa among men in different PSA ranges, stratified by PV medians ( $<60$ and $\geqslant 60 \mathrm{ml}$ ), were calculated. There were 261 men included in the final analysis. $P V$ was the strongest predictor of $P C a$ risk (odds ratio, $0.02 ; P<0.001$ ) compared to other variables. The PCa rates in men with PVs measuring $<60$ and $\geqslant 60 \mathrm{ml}$ in the $10-19.9 \mathrm{ng} \mathrm{ml}^{-1} \mathrm{PSA}$ group were $40.6 \%$ and $15.1 \%$, respectively, while the rates for men with PSAs measuring $20-50 \mathrm{ng} \mathrm{ml}^{-1}$ were $65.1 \%$ and $26.8 \%$. PV is an independent predictor of PCa in men with PSA measuring $10-50 \mathrm{ng} \mathrm{ml}^{-1}$. In clinical practice, particularly for those countries with lower incidences of PCa, PV should be considered when counselling patients with PSAs measuring $10-50 \mathrm{ng} \mathrm{ml}^{-1}$ regarding their PCa risks.
\end{abstract}

Asian Journal of Andrology (2013) 15, 409-412; doi:10.1038/aja.2013.11; published online 8 April 2013

Keywords: prostate biopsy; prostate cancer (PCa); prostate-specific antigen (PSA); prostate volume (PV)

\section{INTRODUCTION}

Currently, transrectal ultrasound (TRUS)-guided prostate biopsy is the 'gold standard' for detecting prostate cancer (PCa). ${ }^{1,2}$ Over the past two decades, prostate-specific antigen (PSA) elevation has become the most common indication for prostate biopsy. However, the specificity of PSA for predicting PCa is low. Free-to-total PSA ratio, PSA velocity, PSA density and transition zone PSA density have all been studied in an attempt to improve the detection rate of PCa and decrease the number of unnecessary prostate biopsies. ${ }^{3-6}$ The most recent American Urological Association guidelines for PCa state that a single threshold PSA value should not be used as an indication for prostate biopsy, but rather, that free/total PSA, age, PSA velocity, PSA density, family history and ethnicity should be considered. ${ }^{7}$

Prostate volume (PV) has been shown to be a predictor of PCa with lower PVs associated with a higher PCa detection rate with TRUS-guided prostate biopsy. ${ }^{8-10}$ However, almost all reports have concentrated on populations within the PSA 'grey zone' (PSA 2.0-10.0 $\mathrm{ng} \mathrm{ml}^{-1}$ ). ${ }^{8,11,12}$ Originally, a Western population was used to define the PSA 'grey zone'. It is well known that Asian men have much lower incidences of PCa compared to other races. ${ }^{13}$ A systematic review revealed that Asian men (primarily Japanese and Korean men) with PSAs of $2.0-10.0 \mathrm{ng} \mathrm{ml}^{-1}$ have lower rates of PCa than men with similar PSAs in Western countries. ${ }^{14}$ Furthermore, we recently reported that the PCa rate in Chinese men with PSAs of 4.0-10.0 $\mathrm{ng} \mathrm{ml}^{-1}$ was $20.2 \%$, much lower than the rates reported for Western men in the literature. ${ }^{6,14}$ Thus, the Asian PSA 'grey zone' should be higher than the traditional Western PSA 'grey zone'. There are limited published data regarding the association of PV and PCa risk in Asian men with PSAs higher than the traditional Western PSA 'grey zone'. Given this lack of data, we evaluated the role of $\mathrm{PV}$ in diagnosing PCa in Asian men with PSAs of $10-50 \mathrm{ng} \mathrm{ml}^{-1}$.

\section{MATERIALS AND METHODS}

Study population

After obtaining institutional review board approval, the records of 699 men who underwent TRUS-guided prostate biopsy between November 1999 and June 2011 were retrieved. Within this cohort, 593 men $(84.8 \%)$ underwent 13 -core prostate biopsies, 40 (5.7\%) underwent 6-core biopsies and $66(9.4 \%)$ underwent 4 - to 15-core biopsies (except for 6 or 13 cores). Two hundred sixty-one men with PSAs measuring $10-50 \mathrm{ng} \mathrm{ml}^{-1}$ that underwent 13 -core prostate biopsies and had complete PV data were included in the study.

Clinical variables evaluation

$\mathrm{PV}$ was measured via TRUS before the prostate biopsies and calculated using the following formula: $\mathrm{PV}(\mathrm{ml})=0.52 \times$ anterior-posterior diameter $(\mathrm{cm}) \times$ transverse diameter $(\mathrm{cm}) \times$ superior-inferior diameter $(\mathrm{cm})$.

The clinical variables included in the analysis were age, PSA at the time of the prostate biopsy, PV and digital rectal examination (DRE) status (positive $v s$. negative). Prostate hardness or nodule on DRE was defined as 'positive', while other findings were defined as 'negative'. $\mathrm{PV}$ was treated as both a continuous and categorical variable (stratified

${ }^{1}$ Department of Urology, Guangzhou First People's Hospital, Guangzhou Medical University, Guangzhou 510180, China; ${ }^{2}$ Postgraduate Institute, Southern Medical University, Guangzhou 510515, China and ${ }^{3}$ Department of Urology, University of lowa, lowa City, IA 52242, USA Correspondence: Dr KJ Xie (xiekeji@sina.com)

Received: 22 November 2012; Revised: 19 December 2012; Accepted: 20 January 2013; Published online: 8 April 2013 
by median). Age and PSA were analysed as continuous variables, and DRE was treated as a categorical variable.

\section{Statistical analysis}

Univariate and multivariate stepwise logistic regressions were used to determine which variables (PV as a continuous or categorical variable, age and PSA as continuous variables and DRE as a categorical variable) were predictive of a positive TRUS biopsy. The men were stratified by median PV $(<60$ and $\geqslant 60 \mathrm{ml})$, and the PCa rates among men with different DRE statuses in different PSA ranges were calculated. Statistical analyses were performed using SPSS (Statistical Package for the Social Sciences) statistical software (version 18.0; SPSS Inc., Chicago, IL, USA). All of the statistical tests were two-sided, and $P<0.05$ was considered significantly different.

\section{RESULTS}

The demographic characteristics of the study cohort are shown in Table 1. Of the 261 subjects included in the study, 95 (36.4\%) were diagnosed with PCa. The median and mean PVs for our study cohort were 60 and $68 \mathrm{ml}$, respectively. The median and mean diagnostic PSA levels for our study cohort were 19.3 and $22.3 \mathrm{ng} \mathrm{ml}^{-1}$, respectively. The median age, PSA and rate of positive DRE in men diagnosed with PCa were all statistically higher than those who did not have PCa (all $P<0.05)$. The median PV for men with $\mathrm{PCa}$ was substantially decreased compared to the men without $\mathrm{PCa}(P<0.001)$.

In a univariate analysis, the risk of $P C a$ was inversely associated with PV. In a stepwise multivariate analysis, PV (as either a continuous or categorical variable), age, PSA and DRE status were all found to be independent predictors of PCa. Men with PVs $\geqslant 60 \mathrm{ml}$ (median) were found to be at a substantially decreased risk of having PCa with an odds ratio of 0.23 when compared to those with a PV of $<60 \mathrm{ml}$ $(P<0.010)$ (Table 2).

Table 1 Characteristics of the study cohort $(n=261)$

\begin{tabular}{|c|c|}
\hline Variables & \\
\hline \multicolumn{2}{|c|}{ Age at time of biopsy (year) } \\
\hline Mean \pm s.d. & $72 \pm 7$ \\
\hline Median (IQR) & $73(68-77)$ \\
\hline \multicolumn{2}{|c|}{ PSA at time of biopsy (ng ml-1) } \\
\hline Mean \pm s.d. & $22.3 \pm 10.5$ \\
\hline Median (IQR) & $19.3(14.1-29.5)$ \\
\hline \multicolumn{2}{|l|}{ Prostate volume (ml) } \\
\hline Mean \pm s.d. & $68 \pm 40$ \\
\hline Median (IQR) & $60(41-85)$ \\
\hline \multicolumn{2}{|l|}{ Biopsy results, $N(\%)$} \\
\hline Prostate cancer & $95(36.4)$ \\
\hline No prostate cancer & $166(63.6)$ \\
\hline \multicolumn{2}{|c|}{ Digital rectal examination ${ }^{\mathrm{a}}, N(\%)$} \\
\hline Positive & $62(23.8)$ \\
\hline Negative & $194(74.3)$ \\
\hline Missing & $5(1.9)$ \\
\hline \multicolumn{2}{|c|}{ Gleason score of the biopsy specimen ( $n=95), N(\%)$} \\
\hline$\leqslant 6$ & $45(47.4)$ \\
\hline 7 & $13(13.7)$ \\
\hline$\geqslant 8$ & 37 (38.9) \\
\hline
\end{tabular}

Table 2 Univariate and multivariate analysis of variables at the time of prostate biopsy in predicting the risk of prostate cancer

\begin{tabular}{|c|c|c|c|c|}
\hline \multirow{2}{*}{ Variables } & \multirow{2}{*}{ Odds ratio } & \multicolumn{3}{|c|}{$(95 \% \mathrm{Cl})$} \\
\hline & & Lower & Upper & $\mathrm{P}$ \\
\hline \multicolumn{5}{|l|}{ Univariate } \\
\hline \multicolumn{5}{|l|}{ Prostate volume $(\mathrm{ml})^{\mathrm{a}}$} \\
\hline$<60$ & Reference & & & \\
\hline$\geqslant 60$ & 0.23 & 0.13 & 0.40 & $<0.001$ \\
\hline \multicolumn{5}{|l|}{ Multivariate } \\
\hline \multicolumn{5}{|c|}{$\begin{array}{l}\text { Prostate volume as a continuous } \\
\text { variable }\end{array}$} \\
\hline Age at biopsy (year) & 1.06 & 1.01 & 1.11 & 0.014 \\
\hline $\log (P S A)$ & 15.02 & 3.06 & 73.72 & 0.001 \\
\hline Log (prostate volume) & 0.02 & 0.01 & 0.10 & $<0.001$ \\
\hline \multicolumn{5}{|c|}{ Digital rectal examination ${ }^{\text {b }}$} \\
\hline Negative & Reference & & & \\
\hline Positive & 3.05 & 1.47 & 6.31 & 0.003 \\
\hline \multicolumn{5}{|c|}{$\begin{array}{l}\text { Prostate volume as a categorized } \\
\text { variable }\end{array}$} \\
\hline Age at biopsy (year) & 1.05 & 1.00 & 1.10 & 0.040 \\
\hline $\log (P S A)$ & 9.74 & 2.07 & 45.83 & 0.004 \\
\hline \multicolumn{5}{|l|}{ Prostate volume $(\mathrm{ml})$} \\
\hline$<60$ & Reference & & & \\
\hline$\geqslant 60$ & 0.23 & 0.12 & 0.43 & $<0.001$ \\
\hline \multicolumn{5}{|l|}{ Digital rectal examination } \\
\hline Negative & Reference & & & \\
\hline Positive & 2.97 & 1.45 & 6.08 & 0.003 \\
\hline
\end{tabular}

Abbreviations: $\mathrm{Cl}$, confidential interval; PSA, prostate-specific antigen.

a The subjects were stratified by prostate volume median $(60 \mathrm{ml})$;

'Prostate hardness or nodule on DRE was defined as 'positive', and other findings were defined as 'negative'.

The rates of PCa in men with PVs of $<60$ and $\geqslant 60 \mathrm{ml}$ in the PSA of $10-19.9 \mathrm{ng} \mathrm{ml}^{-1}$ group were $40.6 \%$ and $15.1 \%$, respectively, while the rates for those with PSAs of $20-50 \mathrm{ng} \mathrm{ml}^{-1}$ were $65.1 \%$ and $26.8 \%$. The PCa rates for men with a PV of $<60$ or $\geqslant 60 \mathrm{ml}$ and with a positive DRE were $72.5 \%$ and $45.5 \%$, respectively, while the rates for those with a negative DRE were $41.8 \%$ and $15.5 \%$, respectively (Table 3). PCa status (cancer and non-cancer) stratified by PV median for the different PSA ranges is shown in Figure 1.

Table 3 Proportion of prostate cancer among men with different DRE statuses and PSA ranges, stratified by PV medians ( $<60 \mathrm{vs.} \geqslant 60 \mathrm{ml})$

\begin{tabular}{lll} 
& \multicolumn{2}{c}{$P V(m l)$} \\
\cline { 2 - 3 } & \multicolumn{1}{c}{$<60 \mathrm{ml}$} & \multicolumn{1}{c}{$\geqslant 60 \mathrm{ml}$} \\
\hline Digital rectal examination ${ }^{\mathrm{a}, \mathrm{b}}$ & & \\
$\quad$ Negative & $41.8 \%(38 / 91)$ & $15.5 \%(16 / 103)$ \\
$\quad$ Positive & $72.5 \%(29 / 40)$ & $45.5 \%(10 / 22)$ \\
$\quad$ Total & $51.1 \%(67 / 131)$ & $20.8 \%(26 / 125)$ \\
PSA (ng ml & $-1)$ & \\
10-19.9 & & \\
$20-50$ & $40.6 \%(28 / 69)$ & $15.1 \%(16 / 103)$ \\
Total & $65.1 \%(41 / 63)$ & $20.8 \%(26 / 125)$ \\
\hline
\end{tabular}

Abbreviations: DRE, digital rectal examination; PSA, prostate-specific antigen; PV, prostate volume.

${ }^{a}$ Because five (1.9\%) subjects were missing DRE data, only 256 subjects were included in the analysis.

b Prostate hardness or nodule on DRE was defined as 'positive', and other findings were defined as 'negative'. 


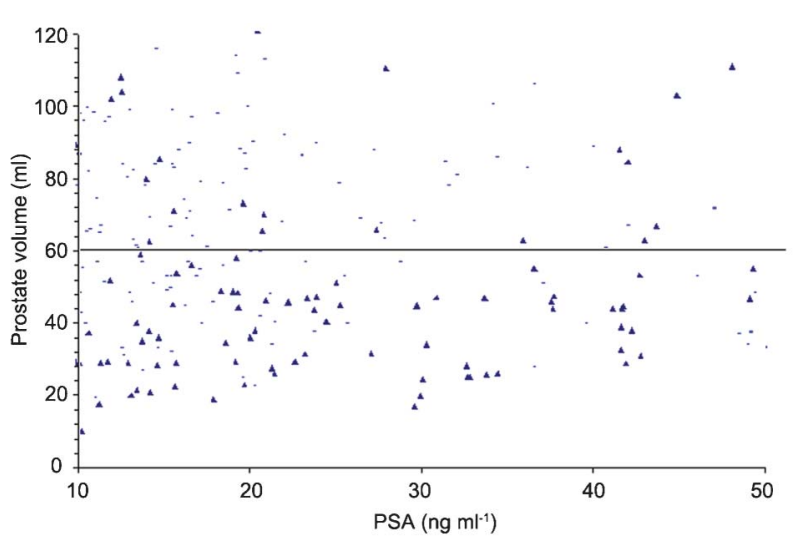

Figure 1 Prostate volumes and PSAs of the subjects' prostate cancer statuses: prostate cancer (triangles) and non-prostate cancer (short lines). Men with prostate volume median (60 ml) (bar). PSA, prostate-specific antigen.

\section{DISCUSSION}

To our knowledge, this study was the first to examine the association between PV and PCa risk in Asian men with PSAs of 10-50 $\mathrm{ng} \mathrm{ml}^{-1}$. We found that decreased PV was associated with a higher risk of PCa detection using TRUS biopsy. Although the association between PV and PCa risk has been evaluated in previous studies, ${ }^{8-10}$ these reports concentrated on populations with PSAs in the traditional 'grey zone' (PSA 2.0-10.0 $\mathrm{ng} \mathrm{ml}^{-1}$ ). The population used to define the 'grey zone' was originally from Western countries. It is well known that men in Western countries have a higher incidence of PCa compared to other races. ${ }^{15}$ It is reasonable then to assume that the PSA 'grey zone' in populations with lower incidences of $\mathrm{PCa}$ is higher than the traditional Western PSA 'grey zone'. In our centre, the rate of PCa in men with a PSA of 2.0-10.0 $\mathrm{ng} \mathrm{ml}^{-1}$ was only $18.7 \%$ (25/134) (data not shown), which is much lower than reports involving only Western men. ${ }^{14}$ This is in line with our hypothesis of Asian men possessing a higher PSA 'grey zone' than Western men. Our findings can be used for counselling patients with PSAs of $10-50 \mathrm{ng} \mathrm{ml}^{-1}$ (regarding their risks of $\mathrm{PCa}$ detection on TRUS biopsy) in countries with lower incidences of PCa.

The mechanism by which smaller PV relays a higher risk of PCa is not known. Some researchers have proposed that it is because of undersampling of larger glands by sextant biopsy, and that simply obtaining more cores from larger prostates could reduce this bias. ${ }^{16}$ Feneley et al. ${ }^{17}$ have reported that men with PSA-detected cancers (stage T1c) have larger prostates than men with stage T2 cancers and without cancer. They suggested that there may be a diagnostic bias because of PSA testing that selects men with larger prostates for cancer screening. Chen et al. ${ }^{18}$ have found that small-volume cancers $(0.5 \mathrm{ml}$ or less) were twice as frequent in men with a PV greater than $50 \mathrm{ml}$. Small-volume tumours comprised $33 \%$ of the cancers in men with PVs $>50 \mathrm{ml}$ whereas, they only accounted for $16 \%$ in men with a $\mathrm{PV}<30 \mathrm{ml}$. They concluded that a lower rate of cancer detection in men with larger PVs was a result of a higher proportion of low-volume cancers in these prostates. Men with large prostates are more likely to undergo biopsy because of elevated PSA levels resulting from benign prostatic components rather than from meaningful cancers.

One strength of our study is that all of the subjects underwent a 13core prostate biopsy. This procedure eliminated any bias introduced by the number of prostate core biopsies taken, even in men with large PVs. In addition, we examined PV as a continuous and categorical variable in multivariate analysis, which produced a more robust result. Additionally, we also examined age and PSA as continuous variables.
Additionally, while other studies have considered these characteristics to be categorical variables, we believe that this may have resulted in a loss of information.

Notably, the median PSA and PV values in men without PCa were higher compared to previous reports from Western countries. ${ }^{19}$ However, our results were comparable to those found in a recent study from the Beijing, China. ${ }^{20}$ Interestingly, elderly men diagnosed with PCa in our study cohort had higher PV than men in Western countries. ${ }^{16}$ There are several possible reasons these discrepancies exist. First, the Chinese men in our cohort who underwent prostatic biopsy were relatively aged because PSA screening to detect early PCa is not generally practiced in China. The increased age of the cohort partially explains the higher PSA and larger PV. Second, we recently reported differences in baseline PSA and PSA velocity in young men without $\mathrm{PCa}$ among native Chinese, Caucasian-American and AfricanAmerican men. We found that young Chinese men have a lower baseline PSA but a higher PSA velocity. ${ }^{21}$ Finally, and most importantly, Chinese men with prostate enlargement may produce and release more PSA per unit PV than Western men. Yu et al. ${ }^{22}$ reported that enlarged prostate tissue in Chinese men has a higher glandular density than that in American men, while American men have a higher percent of stromal tissue compared to Chinese men. These increased glandular components in Chinese men may explain the higher PSA values compared to Western men. This difference also provides a rational explanation for the finding that Chinese men with and without PCa both have increased PVs.

In this study, we also found that the percentage (38.9\%) of men with $\mathrm{PCa}$ and Gleason scores $\geqslant 8$ was much higher than in a Western cohort. However, our findings were in line with another recent report from the Shanghai area, China and a report from Japan. ${ }^{23,24}$ In addition to race, PCa diagnosed at a later stage, with higher PSA values, and with older age at diagnosis might be reasons that explain this discrepancy.

The present study is limited, as it is retrospective in nature. All of the data in our study were obtained from a single, tertiary hospital. The strategies used to diagnose PCa may differ between centres, although they are in the same geographical area. Furthermore, this study was not population-based. It is from a tertiary referral hospital, which makes it possible that our results overestimated the rate of PCa.

\section{AUTHOR CONTRIBUTIONS}

PT, MU and KJX conceived and designed the study. XLJ, XRD, YRL and BW collected the data. PT, XLJ and YRL performed the statistical analyses. PT and MU wrote the manuscript with input from all of the co-authors. All of the authors revised the manuscript and approved the final version.

\section{COMPETING FINANCIAL INTERESTS}

None of the authors have reported direct or indirect financial incentives associated with publishing this article.

\section{ACKNOWLEDGMENTS}

This work was supported by National Natural Science Foundation of China (No. 81072091/H1619), Guangdong Natural Science Foundation Grant, China (No. 10151006001000003) and the Key Project of Guangzhou Municipal Health Bureau Grant, China (No. 20121A021006) to Ping Tang.

1 Chun FK, Epstein JI, Ficarra V, Freedland SJ, Montironi R et al. Optimizing performance and interpretation of prostate biopsy: a critical analysis of the literature. Eur Urol 2010; 58: 851-64. 
2 Shen PF, Zhu YC, Wei WR, Li YZ, Yang J et al. The results of transperineal versus transrectal prostate biopsy: a systematic review and meta-analysis. Asian J Androl 2012; 14: 310-5.

3 Gann PH, Ma J, Catalona WJ, Stampfer MJ. Strategies combining total and percent free prostate specific antigen for detecting prostate cancer: a prospective evaluation. J Urol 2002; 167: 2427-34.

4 Sun L, Moul JW, Hotaling JM, Rampersaud E, Dahm P et al. Prostate-specific antigen (PSA) and PSA velocity for prostate cancer detection in men aged $<50$ years. BJU Int 2007; 99: 753-7.

5 Lam JS, Cheung YK, Benson MC, Goluboff ET. Comparison of the predictive accuracy of serum prostate specific antigen levels and prostate specific antigen density in the detection of prostate cancer in Hispanic-American and white men. J Urol 2003; 170: 451-6.

6 Tang P, Du W, Xie K, Deng X, Fu J et al. Transition zone PSA density improves the prostate cancer detection rate both in PSA 4.0-10.0 and 10.1-20.0 ng/ml in Chinese men. Urol Oncol 2011; e-pub ahead of print 23 August 2011; doi:10.1016/ j.urolonc.2011.06.012.

7 Greene KL, Albertsen PC, Babaian RJ, Carter HB, Gann PH et al. Prostate specific antigen best practice statement: 2009 update. J Urol 2009; 182: 2232-41.

8 Al-Azab R, Toi A, Lockwood G, Kulkarni GS, Fleshner N. Prostate volume is strongest predictor of cancer diagnosis at transrectal ultrasound-guided prostate biopsy with prostate-specific antigen values between 2.0 and $9.0 \mathrm{ng} / \mathrm{mL}$. Urology 2007; 69: 103-7.

9 Colleselli D, Bektic J, Schaefer G, Frauscher F, Mitterberger M et al. The influence of prostate volume on prostate cancer detection using a combined approach of contrastenhanced ultrasonography-targeted and systematic grey-scale biopsy. BJU Int 2007; 100: 1264-7.

10 Uzzo RG, Wei JT, Waldbaum RS, Perlmutter AP, Byrne JC et al. The influence of prostate size on cancer detection. Urology 1995; 46: 831-6.

11 Djavan B, Zlotta AR, Remzi M, Ghawidel K, Bursa B et al. Total and transition zone prostate volume and age: how do they affect the utility of PSA-based diagnostic parameters for early prostate cancer detection? Urology 1999; 54: 846-52.

12 Bruno JJ, 2nd, Armenakas NA, Fracchia JA. Influence of prostate volume and percent free prostate specific antigen on prostate cancer detection in men with a total prostate specific antigen of 2.6 to $10.0 \mathrm{ng} / \mathrm{ml}$. J Urol 2007; 177: 1741-4.
13 Matsuda T, Saika K. Comparison of time trends in prostate cancer incidence (19732002) in Asia, from cancer incidence in five continents, Vols IV-IX. Jpn J Clin Oncol 2009; 39: 468-9.

14 Roddam AW, Duffy MJ, Hamdy FC, Ward AM, Patnick J et al. Use of prostate-specific antigen (PSA) isoforms for the detection of prostate cancer in men with a psa level of 2-10 ng/ml: systematic review and meta-analysis. Eur Urol 2005; 48: 386-99.

15 Xia SJ, Cui D, Jiang Q. An overview of prostate diseases and their characteristics specific to asian men. Asian J Androl. 2012; 14: 458-64.

16 Basillote JB, Armenakas NA, Hochberg DA, Fracchia JA. Influence of prostate volume in the detection of prostate cancer. Urology 2003; 61: 167-71.

17 Feneley MR, Landis P, Simon I, Metter EJ, Morrell CH et al. Today men with prostate cancer have larger prostates. Urology 2000; 56: 839-42.

18 Chen ME, Troncoso P, Johnston D, Tang K, Babaian RJ. Prostate cancer detection: relationship to prostate size. Urology 1999; 53: 764-8.

19 Henderson RJ, Eastham JA, Culkin DJ, Kattan MW, Whatley T et al. Prostate-specific antigen (PSA) and PSA density: racial differences in men without prostate cancer. J Natl Cancer Inst 1997; 89: 134-8.

20 Yu W, Pattar A, He Q, Shan GZ, Jin J. Impact of prostate volume on the diagnostic value of prostate cancer with different biopsy strategies. Beijing Da Xue Xue Bao 2010; 42: 400-3.

21 Tang P, Du W, Xie K, Fu J, Chen $\mathrm{H}$ et al. Characteristics of baseline PSA and PSA velocity in young men without prostate cancer: racial differences. Prostate 2012; 72: 173-80.

22 YuEY, Siegal JA, Meyer GE, Ji XR, Ni XZ et al. Histologic differences in benign prostate hyperplasia between Chinese and American men. Prostate 1997; 31: 175-9.

$23 \mathrm{Na} \mathrm{R}$, Jiang H, Kim ST, Wu Y, Tong S et al. Outcomes and trends of prostate biopsy for prostate cancer in chinese men from 2003 to 2011. PLoS One 2012; 7: e49914.

24 Tanaka N, Fujimoto K, Hirayama A, Yoneda T, Yoshida K et al. Trends of the primary therapy for patients with prostate cancer in nara uro-oncological research group (nuorg): a comparison between the capsure data and the nuorg data. Jpn J Clin Oncol 2010; 40: 588-92. 